\title{
PENGARUH PENGEKANGAN TEXTILE REINFORCED CONCRETE SERAT CANTULA (AGAVE CANTULA ROXB) TERHADAP KUAT TEKAN BETON
}

\author{
S A Kristiawan(1), Edy Purwanto(2), Galang Akbar Wayne Syam Putra ${ }^{(3)}$ \\ 1) Pengajar Fakultas Teknik, Prodi Teknik Sipil, Universitas Sebelas Maret \\ 2) Pengajar Fakultas Teknik, Prodi Teknik Sipil, Universitas Sebelas Maret \\ 3) Mahasiswa Fakultas Teknik, Prodi Teknik Sipil, Universitas Sebelas Maret
}

Jl. Ir. Sutami 36A, Surakarta 57126; Telp.0271-634524. Indonesia, email: galangakbarwsp@gmail.com

\begin{abstract}
Generally Textile Reinforced Concrete (TRC) is a composite consisting of reinforcement in the form of textiles and concrete as a matrix. TRC is one method to repair or strengthen concrete so that the building can function again. TRC was applied as concrete confinement on concrete to determine the effect of cantula fiber woven with variations in compressive strength and development of concrete compressive strength. TRC in this study consists of a matrix of concrete cylinders with dimensions of $75 \mathrm{~mm} \times 150 \mathrm{~mm}$. Reinforcement in the form of woven cantula fibers that are glued together with Polymer Modified Mortar and then bonded to concrete with a thickness of $10 \mathrm{~mm}$. Cantula fiber woven has various axial reinforcement directions according to dimensions of $10 \mathrm{~mm} x$ $10 \mathrm{~mm}, 10 \mathrm{~mm} \times 15 \mathrm{~mm}, 10 \mathrm{~mm} \times 20 \mathrm{~mm}$. Testing on TRC is done at 28 days. The results showed that the compressive strength of the highest confined concrete at TRC 200 was $20.25 \mathrm{MPa}$, while the largest compressive strength development was at TRC 200 at 12.58\%. This shows that cantula fiber confinement affects the compressive strength of TRC and the variation of cantula fiber woven results in different compressive strength developments.
\end{abstract}

Keywords : TRC, Textile Reinforced Concrete, cantula fiber, compressive strength

\begin{abstract}
Abstrak
Secara umum Textile Reinforced Concrete (TRC) adalah suatu komposit yang terdiri dari reinforcement yang berupa tekstil dan beton sebagai matriks. TRC merupakan salah satu metode untuk memperbaiki atau memperkuat beton agar bangunan dapat berfungsi kembali. TRC diaplikasikan sebagai confinement concrete pada beton untuk mengetahui pengaruh anyaman serat cantula dengan variasi pada kuat tekan dan perkembangan kuat tekan beton. TRC pada penelitian ini terdiri dari matriks berupa silinder beton dengan dimensi $75 \mathrm{~mm}$ x $150 \mathrm{~mm}$. Reinforcement berupa anyaman serat cantula yang direkatkan dengan Polymer Modified Mortar kemudian dikekangkan pada beton dengan ketebalan $10 \mathrm{~mm}$. Anyaman serat cantula memiliki variasi arah penulangan aksial sesuai dengan dimensi $10 \mathrm{~mm} \times$ $10 \mathrm{~mm}, 10 \mathrm{~mm} \times 15 \mathrm{~mm}, 10 \mathrm{~mm} \times 20 \mathrm{~mm}$. Pengujian pada TRC dilakukan pada umur 28 hari. Hasil penelitian menunjukkan bahwa nilai kuat tekan beton terkekang yang tertinggi yaitu pada TRC 200 sebesar 20,25 MPa, sedangkan perkembangan kuat tekan terbesar yaitu pada TRC 200 sebesar 12,58\%. Hal ini menunjukkan bahwa pengekangan anyaman serat cantula berpengaruh pada kuat tekan TRC dan variasi anyaman serat cantula mengakibatkan perkembangan kuat tekan yang berbeda.
\end{abstract}

Kata kunci : TRC, Textile Reinforced Concrete, Serat Cantula, Kuat Tekan

\section{PENDAHULUAN}

Kebutuhan beton dalam pekerjaan konstruksi semakin banyak. Secara umum beton bertulang merupakan material pokok utama sebagai struktur penguat. Keunggulan karakteristik seperti durabilitas, kuat tekan dan kekakuan yang tinggi dibandingkan dengan struktur bahan yang lainnya, membuat beton diminati untuk pekerjaan konstruksi. Semakin lama masa layan sebuah bangunan, maka akan terjadi penurunan kekuatan pada struktur beton terutama kolom dan balok yang diakibatkan oleh berbagai macam kondisi seperti bencana gempa, kebakaran dan lain-lain. Maka dari itu diperlukan metode untuk memperbaiki atau memperkuat beton agar kekuatan pada beton dapat meningkat dan bangunan dapat berfungsi sebagaimana mestinya.

Textile Reinforced Mortar (TRM), atau yang juga dikenal dalam literatur internasional sebagai Textile Reinforced Concrete (TRC) merupakan salah satu inovasi untuk memperkuat beton bertulang (Trantafillou dkk, 2018). Textile Reinforced Concrete terdiri dari tekstil, yaitu jerat kain yang terbuat dari anyaman, rajutan atau tenunan setidaknya dua arah yang diresapi dengan pengikat berupa mortar (Triantafillou dkk, 2007). 
Pada textile reinforcement sering digunakan berupa material non-nature,yang berupa serat kaca tahan alkali (AR), aramid, basalt dan carbon fabrics. Oleh karena itu penelitian mencari solusi alternatif untuk reinforcement berbasis nature. Pada penelitian Raharjo (2015) menyatakan bahwa serat Agave Cantula Roxb merupakan serat alam yang memiliki kemampuan mekanik yang tinggi. Hasil survey dari Badan Penilitian dan Pengembangan Industri Departemen Perindustrian Yogyakarta, menyatakan bahwa cantula mempunyai kandungan selulose 64,3\% sehingga serat ini berpotensi sebagai bahan penguat komposit (Raharjo dkk., 2015). Kelebihan yang dimiliki oleh serat cantula itu sendiri diantaranya yaitu harga murah, dapat diuraikan oleh alam, mudah di dapat (producible), kuat, ringan dan kemampuan mekanik yang tinggi (Kurniawan Indra P, Wijang Wisnu Raharjo, 2015).

\section{TINJAUAN PUSTAKA}

\section{Karakteristik Textile Reinforced Concrete (TRC)}

Pada dasarnya Textile Reinforced Concrete (TRC) berupa komposit yang terdiri dari tekstil dan polymer modified mortar yang berfungsi sebagai reinforcement dan beton digunakan sebagai matriks. Reinforcement pada tekstil memberikan dukungan dalam memperkuat struktur beton yang ada di dalam dengan memberikan dukungan kuat lentur, penambahan kekuatan penahan, dan tegangan geser. Efek dari TRC sebagai perkuatan telah berhasil dibuktikan oleh beberapa proyek penelitian. Saat ini penerapan Textile Reinforced Concrete dilapangan menggunakan karbon sebagai reinforcement, sedangkan untuk penggunaan anyaman serat cantula sebagai reinforcement pada Textile Reinforced Concrete perlu dikaji.

\section{Uji Tekan}

Menurut SNI 03-1974-2011 kuat tekan beton adalah besarnya beban per satuan luas, yang dapat menyebabkan benda uji yang berupa beton hancur. Beban tersebut berupa gaya tekan yang dihasilkan oleh mesin tekan. Untuk benda uji berbentuk silinder mempunya nilai konversi 0,83 . Benda uji yang digunakan pada penelitian ini adalah silinder dengan diameter $75 \mathrm{~mm}$ dan panjang $150 \mathrm{~mm}$.

Perhitungan kuat tekan beton diperoleh berdasarkan rumus :

$$
\mathrm{fc}=\frac{P}{A}
$$

Dimana

$\mathrm{fc} \quad=$ kuat tekan beton $(\mathrm{MPa})$

$\mathrm{P} \quad=$ beban maksimum total $(\mathrm{N})$

A = luas dari permukaan yang dibebani $\left(\mathrm{mm}^{2}\right)$

Perhitungan kuat tekan beton terkekang menggunakan model persamaan dari Wu and Zhou (2010) dimana:

$$
\begin{gathered}
f_{l}=\frac{2 f_{f} t}{d} \\
\frac{f_{c c}^{\prime}}{f_{c o}^{\prime}}=\frac{f_{l}}{f_{c o}^{\prime}}+\sqrt{\left(\frac{16.7}{f_{c o}^{\prime 0.42}}-\frac{f_{c o}^{\prime 0.42}}{16.7}\right) \frac{f_{l}}{f_{c o}^{\prime}}+1}
\end{gathered}
$$

Dimana :

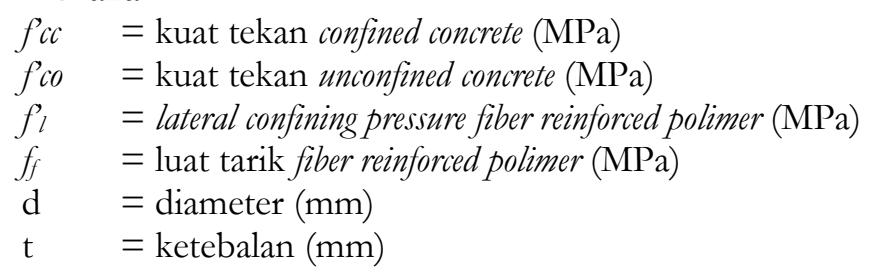

\section{METODE}

\section{Material}

Material utama pada textile reinforced concrete berupa komposit yang terdiri dari tekstil yang berfungsi sebagai reinforcement dan fine-grained concrete digunakan sebagai matriks. Bahan-bahan yang perlu dipersiapkan untuk matriks dalam penelitian antara lain.

1. Agregat halus yang digunakan adalah pasir yang memenuhi syarat lolos saringan $1,18 \mathrm{~mm}$.

2. Agregat kasar yang digunakan adalah batu pecah yang memiliki ukuran maksimum $20 \mathrm{~mm}$.

3. Semen dengan jenis Pozzolan Portland (PPC).

4. Anyaman serat cantula, dengan variasi anyaman $10 \mathrm{~mm} \times 10 \mathrm{~mm}, 10 \mathrm{~mm} \times 15 \mathrm{~mm}, 10 \mathrm{~mm} \times 20 \mathrm{~mm}$.

5. Superplasticizer digunakan untuk meningkatkan workability pada benda uji. 
6. Accelerator SIKACIM® sebanyak $50 \%$ dari jumlah air yang digunakan untuk membuat mortar. Accelerator berguna untuk mempercepat pengerasan pada mortar dan meningkatkan kekuatan mortar pada umur awal.

7. Envirotac Polymer merupakan bahan tambah yang berguna sebagai perekat pada mortar.

\section{Benda Uji}

Benda uji yang digunakan pada penelitian ini berupa silinder beton dengan diameter $75 \mathrm{~mm}$ dan tinggi $150 \mathrm{~mm}$. Pengujian benda uji dilakukan dengan cara tekan langsung pada umur 28 hari dengan menggunakan UTM. Reinforcement yang digunakan adalah anyaman serat cantula yang di tempelkan ke beton menggunakan Polymer Modified Mortar (PMM) dengan ketebalan $10 \mathrm{~mm}$. Variasi matriks yang diuji berupa anyaman serat cantula pada textile reinforced concrete (TRC). Variasi anyaman serat cantula yang akan diteliti yaitu $10 \mathrm{~mm} \times 10 \mathrm{~mm}, 10 \mathrm{~mm}$ x 15 $\mathrm{mm}, 10 \mathrm{~mm} \times 20 \mathrm{~mm}$.

\section{HASIL DAN PEMBAHASAN}

\section{Hasil Pengujian Textile Reinforced Concrete}

Kuat tekan TRC didapatkan dengan dua cara yaitu uji kuat tekan beton aktual dan perhitungan kuat tekan TRC dengan permodelan.

\section{Hasil Pengujian Kuat Tekan Aktual}

Pengujian kuat tekan beton bertujuan untuk mengetahui beban maksimum yang dapat ditahan oleh beton hingga beton retak atau hancur, pengujian dilaksanakan menggunakan Universal Testing Machine. Hasil Pengujian Kuat Tekan Aktual didapatkan dari pengujian kuat tekan. Rekapitulasi hasil uji kuat tekan dapat dilihat pada tabel 1.

Tabel 1 Hasil Uji Kuat Tekan Aktual TRC dengan Anyaman Serat Cantula

\begin{tabular}{|c|c|c|c|c|}
\hline Kode & $\mathrm{d}(\mathrm{mm})$ & $1(\mathrm{~mm})$ & f'c Kuat Tekan (MPa) & f'c Kuat Tekan Rata" (MPa) \\
\hline TRC 000 & 75 & 150 & 16,40 & \multirow{5}{*}{17,99} \\
\hline TRC 000 & 75 & 150 & 16,97 & \\
\hline TRC 000 & 75 & 150 & 15,27 & \\
\hline TRC 000 & 75 & 150 & 23,19 & \\
\hline TRC 000 & 75 & 150 & 18,10 & \\
\hline TRC 100 & 75 & 150 & 16,40 & \multirow{5}{*}{18,33} \\
\hline TRC 100 & 75 & 150 & 20,36 & \\
\hline TRC 100 & 75 & 150 & 16,97 & \\
\hline TRC 100 & 75 & 150 & 21,49 & \\
\hline TRC 100 & 75 & 150 & 16,40 & \\
\hline TRC 150 & 75 & 150 & 17,54 & \multirow{5}{*}{19,80} \\
\hline TRC 150 & 75 & 150 & 21,49 & \\
\hline TRC 150 & 75 & 150 & 22,63 & \\
\hline TRC 150 & 75 & 150 & 21,49 & \\
\hline TRC 150 & 75 & 150 & 15,84 & \\
\hline TRC 200 & 75 & 150 & 23,19 & \multirow{5}{*}{20,25} \\
\hline TRC 200 & 75 & 150 & 16,40 & \\
\hline TRC 200 & 75 & 150 & 17,54 & \\
\hline TRC 200 & 75 & 150 & 20,93 & \\
\hline TRC 200 & 75 & 150 & 23,19 & \\
\hline
\end{tabular}




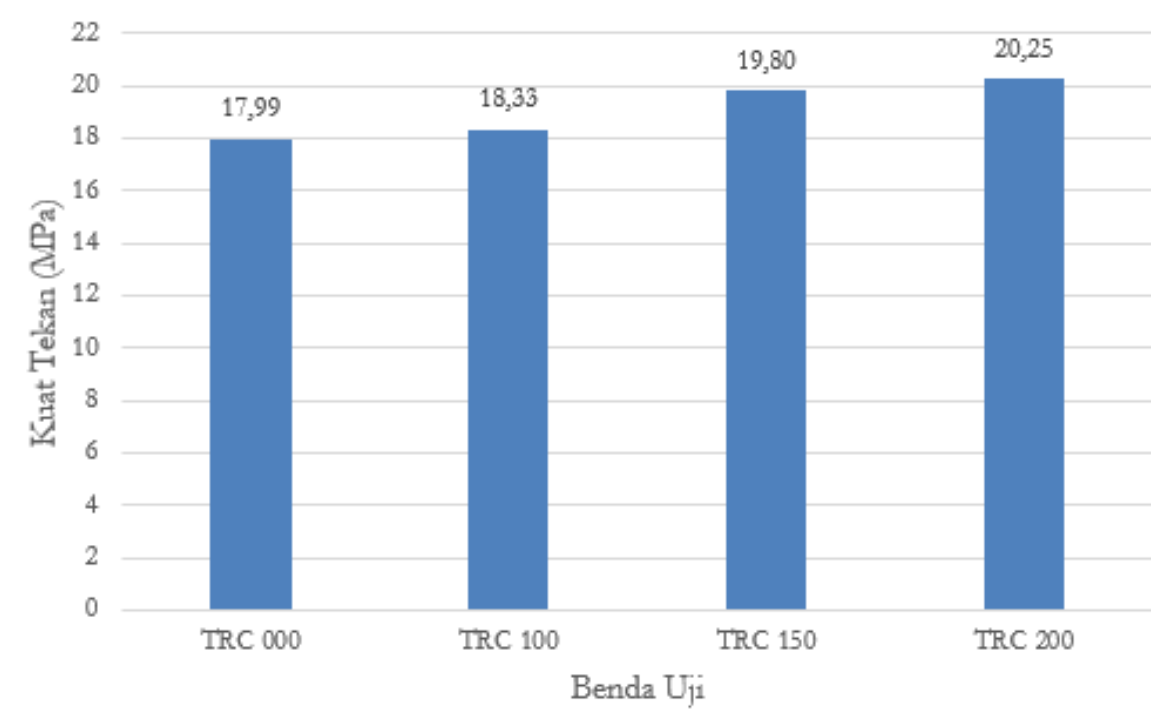

Gambar 1 Diagram Hasil Uji Kuat Tekan TRC dengan Anyaman Serat Cantula

Dari tabel dan gambar diatas dapat diketahui bahwa kuat tekan optimal Textile Reinforced Concrete terjadi pada TRC 200 yaitu sebesar 20,25 MPa. Hal ini dikarenakan anyaman pada arah aksial pada TRC 200 lebih renggang daripada TRC 100 dan TRC 150. Serta terjadi perkembangan kuat tekan dari TRC 000 yang merupakan beton normal atau beton tidak terkekang sebesar 17,99 MPa terhadap TRC 200.yaitu sebesar 20,25 MPa. Pada pembahasan selanjutnya kuat tekan TRC 000 akan dianggap sebagai f'co yang mana merupakan beton normal atau beton tidak terkekang.

\section{Hasil Uji Kuat Tarik}

Hasil uji kuat tarik didapatkan dari penelitian Firman (2019) menggunakan Polymer Modified Mortar (PMM) berserat cantula dengan bentuk jam pasir yang dapat dilihat pada tabel 2.

Tabel 2 Hasil Uji Kuat Tarik Langsung Polymer Modified Mortar berserat cantula

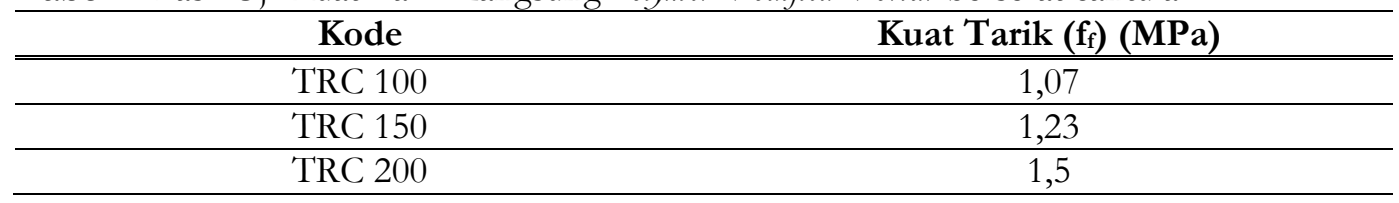

Dari hasil uji tarik diatas didapatkan nilai lateral confining pressure beton terkekang (fl) dengan persamaan [2]. Tabel Hasil Perhitungan Lateral confining pressure (fl) dapat dilihat pada tabel 3.

Tabel 3 Hasil Perhitungan Lateral confining pressure (fl)

\begin{tabular}{ccccc}
\hline Kode & $\mathbf{d}(\mathbf{m m})$ & $\mathbf{t}(\mathbf{m m})$ & Kuat Tarik $\left(\mathbf{f}_{\mathbf{f}}\right) \mathbf{( M P a )}$ & $\begin{array}{c}\text { Lateral confining pressure (fl) } \\
(\mathbf{M P a})\end{array}$ \\
\hline \hline TRC 100 & 75 & 10 & 1,07 & 0,28 \\
\hline TRC 150 & 75 & 10 & 1,23 & 0,33 \\
\hline TRC 200 & 75 & 10 & 1,5 & 0,4 \\
\hline
\end{tabular}

Hasil Perhitungan Kuat Tekan TRC dengan Permodelan

Hasil Perhitungan kuat tekan TRC permodelan didapatkan dengan cara menghubungkan kuat tekan beton normal atau beton tidak terkekang ( $\mathrm{f}(\mathrm{CO})$ dan lateral confining pressure $\left(f_{l}\right)$ yang mana kemudian menghasilkan kuat tekan beton terkekang ( $\mathrm{f} c \mathrm{c}$ ) menggunakan persamaan [3]. Tabel Hasil Kuat Tekan TRC dengan Permodelan dapat dilihat pada tabel 4 .

Tabel 4 Hasil Kuat Tekan TRC dengan Permodelan

\begin{tabular}{cccc}
\hline Kode & $\mathbf{f}^{\prime} \mathbf{c o} \mathbf{( M P a )}$ & $\mathbf{f l} \mathbf{( M P a )}$ & $\mathbf{f}^{\prime} \mathbf{c c} \mathbf{( M P a )}$ \\
\hline \hline TRC 100 & 17,99 & 0,28 & 18,94 \\
\hline TRC 150 & 17,99 & 0,33 & 19,08 \\
\hline
\end{tabular}




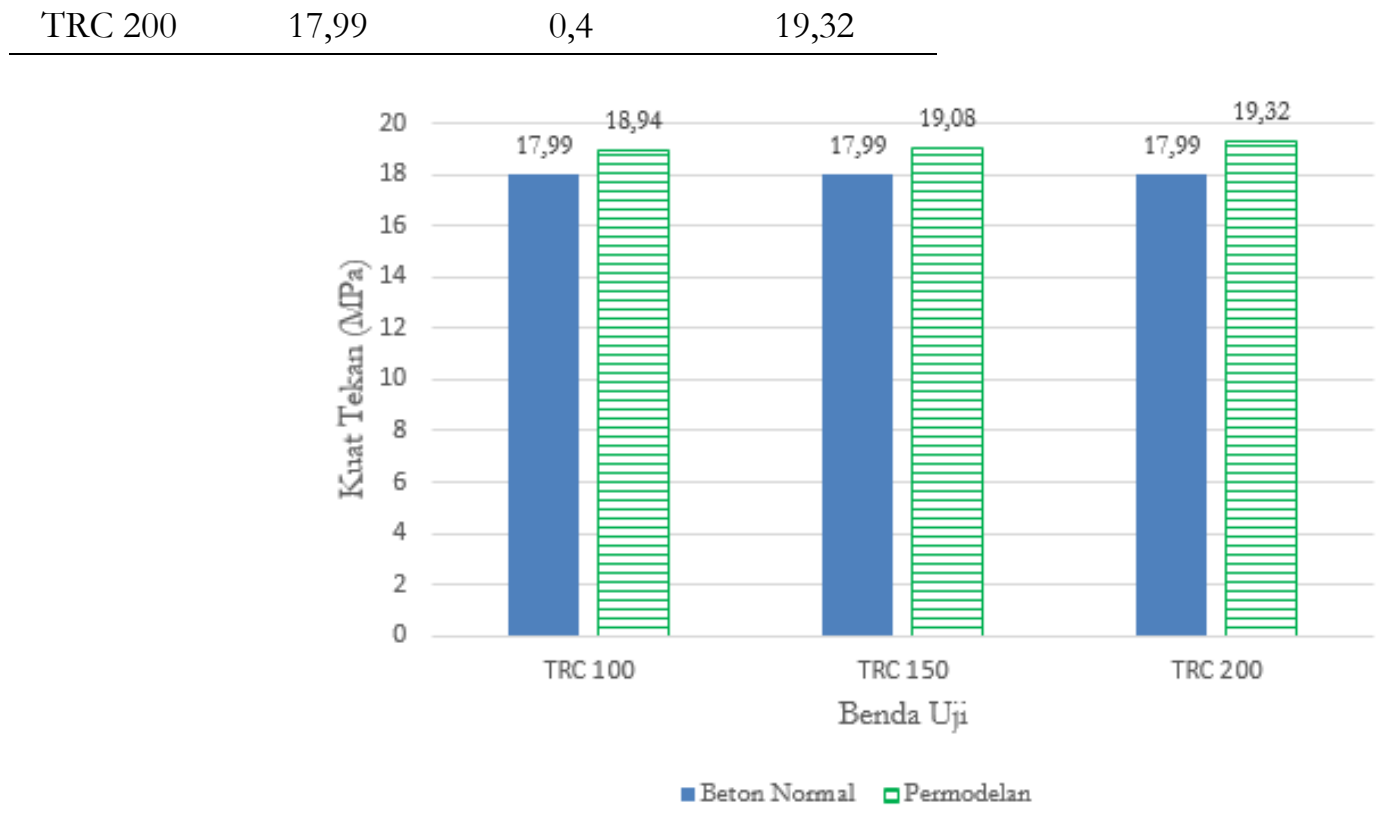

Gambar 2 Diagram Perbandingan Beton Normal dengan Beton TRC Menggunakan Uji Tekan dan Permodelan

\section{Rekapitulasi Analisis Perhitungan}

Setelah didapatkan hasil uji kuat tekan aktual dan hasil uji kuat tekan TRC permodelan maka dapat dilihat keakuratan perbandingan antara hasil uji kuat tekan aktual dengan hasil kuat tekan permodelan, serta didapatkan pula hasil perkembangan kuat tekan dari beton tidak terkekang ( $\mathrm{f}(\mathrm{co})$ dengan beton terkekang ( $\mathrm{f}^{\prime} \mathrm{cc}$ ) dapat dilihat pada tabel 5.

Tabel 5 Rekapitulasi Hasil Uji Kuat Tekan Aktual TRC dan Permodelan

\begin{tabular}{ccccccc}
\hline Kode & $\begin{array}{c}\mathbf{f}^{\prime} \mathbf{c o} \\
\mathbf{M P a}\end{array}$ & Aktual & Permodelan & $\begin{array}{c}\text { Perbandingan } \\
\text { Aktual/Permodelan }\end{array}$ & $\begin{array}{c}\text { Margin } \\
\text { of } \\
\text { Error } \\
\mathbf{\%}\end{array}$ & $\begin{array}{c}\text { Perkembangan } \\
\text { Kekuatan } \\
\text { Tekan \% }\end{array}$ \\
\hline $\begin{array}{c}\text { TRC } \\
100\end{array}$ & 17,99 & 18,33 & 18,94 & 0,97 & 3,22 & 1,89 \\
\hline $\begin{array}{c}\text { TRC } \\
150\end{array}$ & 17,99 & 19,80 & 19,08 & 1,04 & 3,75 & 10,06 \\
\hline $\begin{array}{c}\text { TRC } \\
200\end{array}$ & 17,99 & 20,25 & 19,32 & 1,05 & 4,84 & 12,58 \\
\hline
\end{tabular}

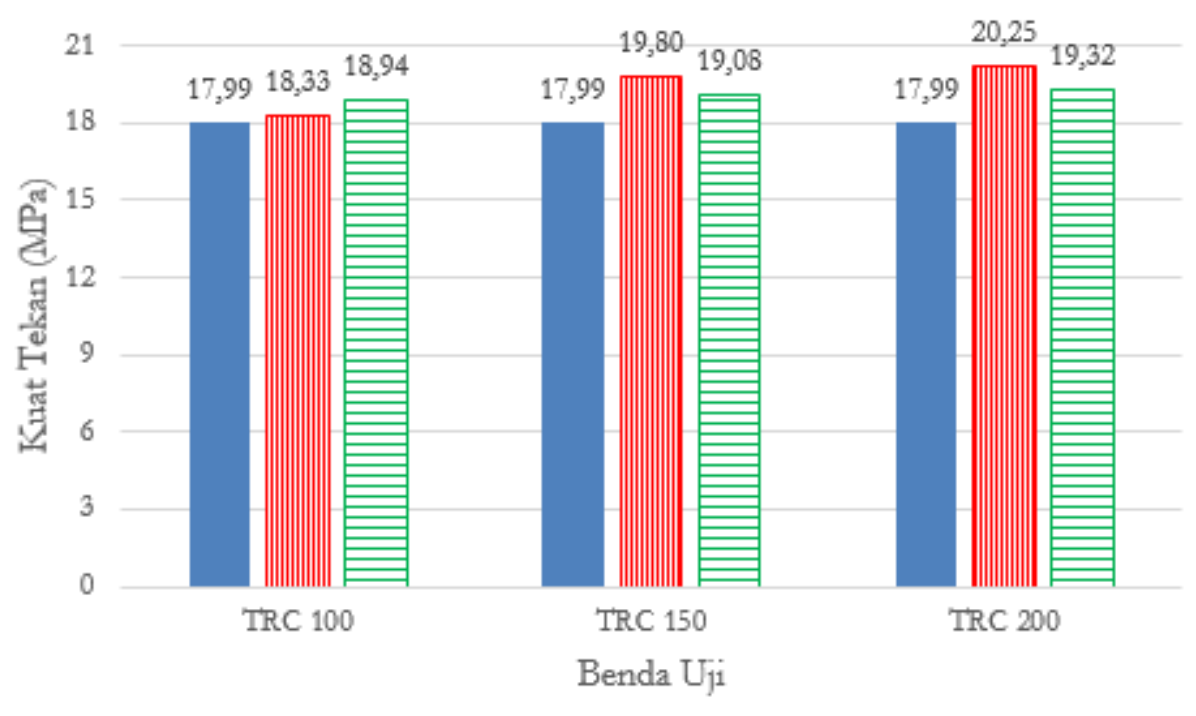

a Beton Normal mU $U_{\ddot{\mu}}^{-}$Kuat Tekan $\boxminus$ Permodelan 
Gambar 3 Diagram Perbandingan Beton Normal dengan Beton TRC Menggunakan Uji Tekan dan Permodelan

Berdasarkan tabel rekapitulasi diatas didapatkan bahwa nilai kuat tekan aktual ( $\mathrm{fcc}$ ) yang paling tinggi adalah TRC 200 sebesar 20,25 Mpa. Hal ini menjelaskan bahwa pengekangan beton dengan menggunakan variasi anyaman serat cantula dapat memberikan pengaruh pada kuat tekan beton. Nilai margin of error pada perbandingan uji kuat tekan beton terkekang dengan perhitungan kuat tekan permodelan berkisar 3,22\% - 4,84\%. Perkembangan kuat tekan paling besar dari beton tidak terkekang terhadap kuat tekan aktual beton terkekang sebesar $12,58 \%$ yaitu terjadi pada TRC 200. Hal ini menjelaskan bahwa pengekangan beton jarak variasi anyaman serat cantula memberikan pengaruh pada perkembangan kuat tekan beton.

\section{KESIMPULAN}

Berdasarkan hasil pengujian dan analisis kuat tekan Textile Reinforced Concrete dengan anyaman serat cantula didapatkan kesimpulan sebagai berikut :

1. Pada TRC 200 menghasilkan kuat tekan paling tinggi sebesar 20,25 MPa. Hal ini menjelaskan bahwa pengekangan beton dengan menggunakan variasi anyaman serat cantula dapat memberikan pengaruh pada kuat tekan beton.

2. Pada TRC 200 menghasilkan perkembangan kuat tekan paling tinggi sebesar $12,58 \%$. hal ini menjelaskan bahwa pengekangan beton dengan menggunakan variasi anyaman serat cantula dapat memberikan pengaruh pada perkembangan kuat tekan beton.

\section{REFERENSI}

Pratama, Firman.2019. Analisis Modulus Elastisitas dan Kuat Tarik Pada Polymer Modified Mortar (PMM) dengan Penambahan Serat Cantula (Agave Cantula Roxb). Surakarta: Universitas Sebelas Maret Surakarta.

Raharjo, Wijang W. 2015. Sifat Tarik dan Lentur Komposit rHDPE/Serat Cantula dengan Variasi Panjang Serat. Banjarmasin: Proceeding Seminar Tahunan Teknik Mesin XIV.

SNI 03-1974-2011. 2011. Cara Uji Kuat Tekan Beton Dengan Benda Uji Silinder. Jakarta : Badan Standarisasi Nasional. Triantafillou, P.E. 2007. Textile-Reinforced Mortar (TRM) versus FRP Confinement in Reinforced Concrete Columns. ACI Structural Journal.

Triantafillou, P.E. 2018. Strengthening of Concrete Structures with Textile Reinforced Mortars. State-ofthe-Art Review. ASCE.

Wu Y. F., Zhou Y., Unified strength model based on Hoek-Brown failure criterion for circular and squeare concrete columns confined by FRP. ASCE Journal of Composites for Construction, V. 14, No. 2, 175-184, 2010. 